\title{
SIMULASI PEMANFAATAN DYNAMIC ROUTING PROTOCOL EIGRP PADA ROUTER DI JARINGAN UNIVERSITAS ISLAM RIAU BESERTA AUTENTIKASINYA
}

\author{
Abdul Syukur ${ }^{1}$, Liza Julianti² \\ Program Studi Teknik Infomatika, Fakultas Teknik, Universitas Islam Riau \\ J1. Kaharuddin Nasution No. 113 Marpoyan, Pekanbaru, Riau \\ Email: ${ }^{1}$ abdulsyukur@eng.uir.ac.id, ${ }^{2}$ lizajulianti3@gmail.com
}

(Naskah masuk: 11 November 2017, diterima untuk diterbitkan: 16 Januari 2018)

\begin{abstract}
Abstrak
Router membutuhkan routing protocol dalam menentukan rute terbaik yang akan dipilih. Routing dynamic adalah sebuah proses yang memiliki dan membuat tabel routing secara otomatis, dengan mendengarkan lalu lintas jaringan dan juga dengan saling berhubungan antara router lainnya. Pada penelitian simulasi menggunakan protokol EIGRP dengan implementasi IPv4 pada topologi star dan ring. Parameter yang akan diuji berupa throughput dan delay. Selain itu penelitian ini juga memberikan otentikasi jaringan dengan radius server menggunakan zeroshell. Dari hasil pengujian yang didapat nilai throughput dan delay termasuk dalam kategori baik yang telah memenuhi standar ITU-T dan zeroshell dapat berjalan dengan baik dengan protokol EIGRP.
\end{abstract}

Kata Kunci: routing dynamic, EIGRP, radius server, throughput

\begin{abstract}
Routers need routing protocol to determine the best route to be selected. Dynamic routing is a process that has and makes the routing tables automatically, by listening to the network traffic and also interconnected with other routers. In the simulation study using EIGRP protocol with IPv4 implementation on star and ring topology. The parameters to be tested such as throughput and delay. In addition, this study also provides the network with a radius authentication server using Zeroshell. From the test results obtained value of throughput and delay are included in both categories that meets the standards ITU-T and Zeroshell can run well with EIGRP protocols.
\end{abstract}

Key words: dynamic routing, EIGRP, radius server, throughput

\section{PENDAHULUAN}

Didunia pendidikan internet menjadi kebutuhan umum, internet menjadi salah satu kebutuhan yang sangat penting bagi manusia. Dengan jasa internet, semua kegiatan bisa dilakukan. Contohnya berbagi ilmu pengetahuan atau mendapatkan ilmu pengetahuan, bahkan internet sekarang juga bisa dijadikan tempat untuk berwirausaha. Internet tercipta karena adanya alat-alat jaringan yang mempunyai fungsinya masing-masing seperti router, switch atau hub, kabel jaringan, dan sebagainya.

Di Universitas Islam Riau (UIR) pengguna internet semakin banyak, dan ini akan terus berkembang untuk masa yang akan datang. Berdasarkan data dari Biro Administrasi Informasi dan Teknologi (BAIT) topologi UIR saat ini berbentuk Topologi Star, karena untuk saat ini hanya ada satu router utama yang mengatur lalu lintas jaringan. Gedung utama yang terhubung ke BAIT yaitu Gedung Fisipol, Hukum, Psikologi, Fkip C,
Labor Pertanian, Rusunawa, Fkip A dan B, Fekon, Fai, Rektorat, Pertanian, Teknik, dan Pasca Sarjana.

Berdasarkan data dari BAIT konfigurasi routing saat ini dilakukan secara statis. Routing statis mempunyai kelemahan, salah satu kelemahannya yaitu tabel routing disetting secara manual oleh admin jaringan. Routing statis tidak menggunakan protokol jaringan sehingga apabila pada saat routing tabel dibuat atau dihapus harus dilakukan secara manual oleh admin jaringan. Untuk mengatasi hal tersebut akan dibangun simulasi routing dynamic dengan protokol EIGRP.

Konfigurasi dynamic cocok untuk jaringan berskala besar dan protokol EIGRP mempunyai fitur backup route, dimana jika terjadi perubahan pada network, EIGRP memberikan tabel routing terbaik, selain itu EIGRP juga menyimpan backup terbaik untuk setiap route, sehingga setiap kali terjadi kegagalan pada jalur utama, maka EIGRP menawarkan jalur alternatif tanpa menunggu waktu convergence. 
Internet Protokol (IP) menjadi komponen yang penting untuk mengatur komunikasi internet. IP yang digunakan saat ini mengikuti standar Internet Protokol versi 4 (IPv4). Dalam hal ini penelitian mewujudkan simulasi routing protokol dynamic EIGRP dalam jaringan IPv4. Tujuan penelitian ini adalah memberikan gambaran kerja EIGRP di lingkungan UIR, serta memberikan otentikasi jaringan pada saat jaringan diakses oleh user. EIGRP akan memberikan routing table yang berisi informasi mengenai keadaan jaringan pada saat itu.

\section{Tujuan dari penelitian ini adalah:}

1. Meningkatkan ketersediaan atau availability koneksi antar komputer di jaringan internal UIR dengan menggunakan protokol routing dinamik EIGRP.

2. Memberikan gambaran kinerja protokol EIGRP untuk lingkungan internal UIR.

3. Memberikan otentikasi pada jaringan yang akan terhubung ke jaringan internal UIR.

\section{Identifikasi Masalah}

1. Semakin meningkatnya kebutuhan internet di UIR maka akan semakin besar ruang lingkup jaringan yang akan dibutuhkan. Routing statik akan memperlambat kinerja admin jaringan dalam mengelola jaringan berskala besar.

2. Jika ada perubahan pada network maka admin jaringan harus merubah secara manual.

3. Tabel routing harus di setting secara manual oleh admin jaringan.

\section{Teknik Pengumpulan Data}

Dalam proses pengumpulan data, untuk mendapatkan data yang benar dan meyakinkan agar hasil yang dicapai tidak menyimpang dari tujuan yang telah ditetapkan sebelumnya, penulis melakukan langkah-langkah penelitian sebagai berikut:

\section{Analisis}

Metode ini gunanya untuk megidentifikasi masalah dan menjabarkan cara berfikir untuk membuat sebuah flowchart. Analisa ini dilakukan untuk mencari solusi pemecahan dari masalah yang telah dirumuskan sebelumnya.

2. Perancangan

Tahap ini menterjemahkan spesifikasi kebutuhan yang telah didapat pada tahap analisis kedalam bentuk arsitektur perangkat untuk diimplementasikan kepada aplikasi yang dibuat.

3. Pengujian

Dalam tahap pengujian ini akan dilakukan evaluasi dengan cara implementasi terhadap simulasi yang dibangun.

\section{Dokumentasi}

Pada proses dokumentasi, penulis juga melakukan studi pustaka, membaca dan mempelajari dokumen-dokumen, buku-buku acuan, serta sumber lainnya yang berkaitan dengan penelitian untuk dijadikan referensi belajar.

\section{Parameter Kerja} lain:

Parameter yang diukur pada penelitian ini antara

1. Throughput

Analisa throughput merupakan kecepatan transfer data efektif, yang diukur dalam bit per second (bps). Throughput merupakan jumlah total kedatangan paket yang sukses yang diamati pada sisi client/tujuan selama selang waktu tertentu dibagi oleh durasi selama waktu tersebut.

throughput $=\frac{\text { jumlah data yang dikirim }}{\text { waktu pengiriman data }}$

2. Delay

Waktu yang dibutuhkan untuk sebuah paket untuk mencapai tujuan, karena adanya antrian yang panjang, atau mengambil rute yang lain untuk menghindari kemacetan, delay maksimal adalah 300ms.

$$
\begin{aligned}
\text { Delay }=\text { waktu } \text { paket diterima } \\
\\
- \text { total paket dikirim }
\end{aligned}
$$

Tabel 1. Standar Delay berdasarkan ITU-T G.114

\begin{tabular}{ll}
\hline \multicolumn{1}{c}{ Delay $(\mathrm{ms})$} & \multicolumn{1}{c}{ Kualitas } \\
\hline $0-150$ & Baik \\
\hline $150-400$ & Cukup, masih dapat diterima \\
\hline$>400$ & Buruk \\
\hline
\end{tabular}

\section{Analisis Sistem Yang Sedang Berjalan}

Topologi jaringan UIR saat ini berbentuk topologi Star dengan router utama berada di gedung BAIT. Router utama masih dikonfigurasi dengan routing statik dengan menggunakan IPv4. Kebutuhan internet di UIR untuk masa yang akan datang akan semakin meningkat, untuk memudahkan admin dalam mengelola jaringan disini penulis memberikan solusi untuk menggunakan routing dynamic EIGRP dengan pengalamatan IPv4. 


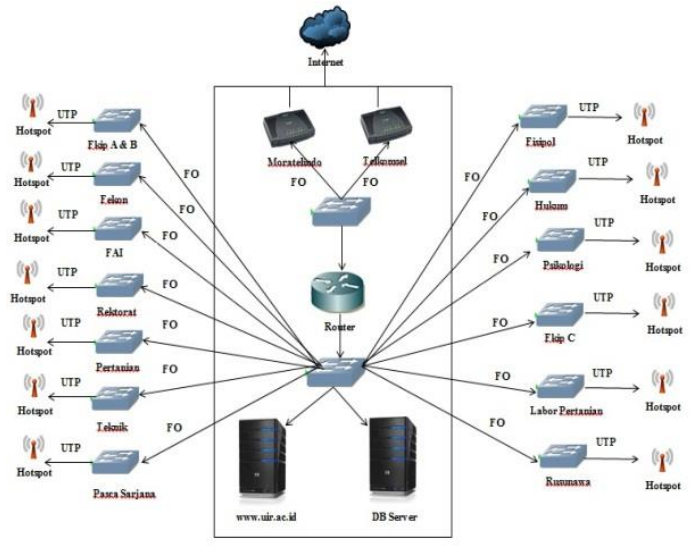

Gambar 1. Topologi Internal UIR

\section{Pengembangan Dan Perancangan Sistem}

\subsection{Topologi Fisik}

Topologi Fisik adalah struktur atau rangkaian dari suatu jaringan atau bagaimana sebuah jaringan didesain.

Di lingkungan Universitas Islam Riau terdapat 12 fakulltas yang terhubung ke BAIT. BAIT merupakan gedung utama yang mempunyai router yang menjadi lalu lintas jaringan di UIR. Berikut ini pada gambar 2 penjelasan tentang tata letak fakultas UIR di Lingkungan UIR.

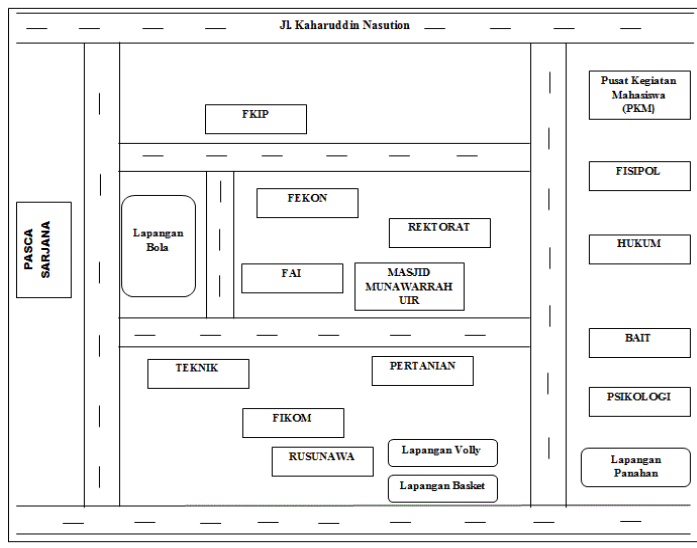

Gambar 2. Skema Lingkungan UIR

Tabel 2. Keterangan jarak Fakultas ke BAIT

\begin{tabular}{|c|c|c|c|}
\hline No & Fakultas & Tujuan & $\begin{array}{c}\text { Jarak } \\
\text { (Meter) }\end{array}$ \\
\hline 1 & HUKUM & \multirow{12}{*}{ BAIT } & 130 \\
\hline 2 & FISIPOL & & 240 \\
\hline 3 & FKIP & & 310 \\
\hline 4 & REKTORAT & & 170 \\
\hline 5 & FEKON & & 240 \\
\hline 6 & FAI & & 190 \\
\hline 7 & PERTANIAN & & 110 \\
\hline 8 & FIKOM & & 230 \\
\hline 9 & TEKNIK & & 370 \\
\hline 10 & PASCA & & 460 \\
\hline 11 & PSIKOLOGI & & 50 \\
\hline 12 & RUSUNAWA & & 450 \\
\hline
\end{tabular}

Tabel 3. Keterangan jarak antar Fakultas sesuai Topologi Simulasi

\begin{tabular}{|c|l|c|}
\hline No & \multicolumn{1}{|c|}{ Fakultas } & $\begin{array}{c}\text { Jarak } \\
\text { (Meter) }\end{array}$ \\
\hline 1 & BAIT ke HUKUM & 130 \\
\hline 2 & HUKUM ke FISIPOL & 110 \\
\hline 3 & FISIPOL ke FKIP & 190 \\
\hline 4 & FKIP ke REKTORAT & 150 \\
\hline 5 & FEKON ke FAI & 60 \\
\hline 6 & FAI ke PERTANIAN & 160 \\
\hline 7 & PERTANIAN ke FIKOM & 130 \\
\hline 8 & FIKOM ke TEKNIK & 90 \\
\hline 9 & TEKNIK ke PASCA & 450 \\
\hline 10 & PASCA ke PSIKOLOGI & 400 \\
\hline 11 & PSIKOLOGI ke RUSUNAWA & 450 \\
\hline 12 & RUSUNAWA ke BAIT & \\
\hline
\end{tabular}

Pada tabel 2 diatas merupakan informasi jarak antara fakultas dengan fakultas lainnya. Fakultas yang diuji berdasarkan topologi simulasi yang dibangun. Dan untuk pengukuran jarak dilakukan menggukan aplikasi yang terintegrasi dengan Google Maps.

\subsection{Topologi Logic}

Topologi logic adalah topologi yang menggambarkan hubungan secara logika yang terjadi pada masing-masing komputer dalam jaringan.

Pada rancangan ini menggambarkan topologi star yang akan dibuat nanti pada GNS3 dengan skenario jalur dan IP address yang sudah ditentukan pada gambar 4 dibawah ini:

Tabel 4. Address Topologi Star

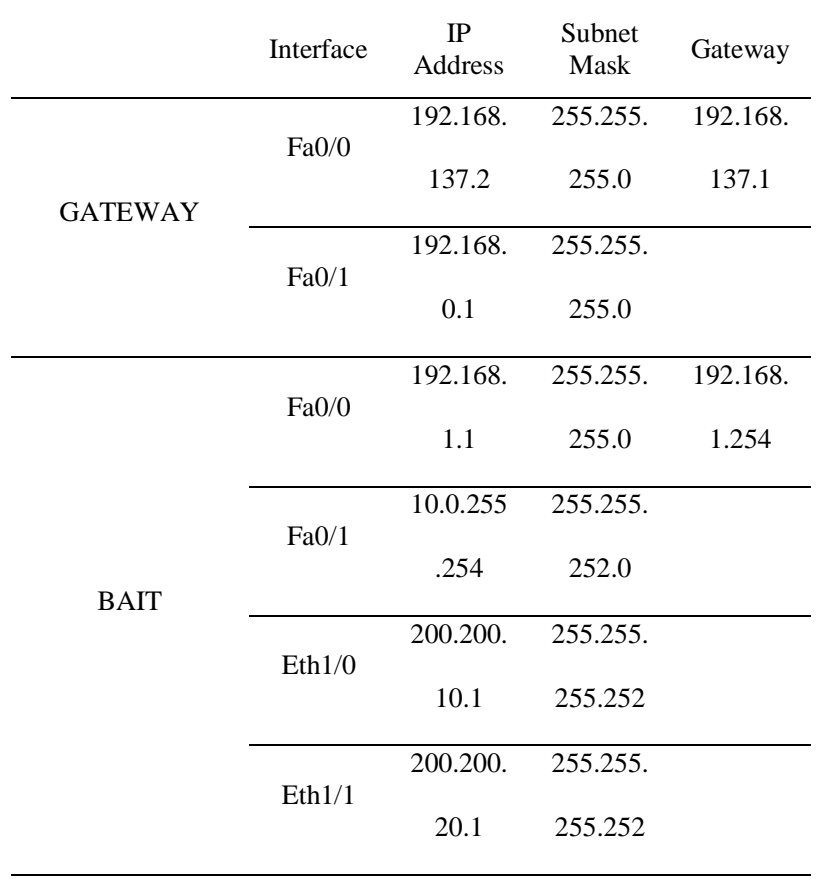


26 Jurnal Teknologi Informasi dan Ilmu Komputer (JTIIK), Vol. 5, No.1, Maret 2018, hlm. 23-34

\begin{tabular}{|c|c|c|c|c|c|c|c|c|c|}
\hline & Eth1/2 & $\begin{array}{c}200.200 . \\
30.1\end{array}$ & $\begin{array}{l}255.255 . \\
255.252\end{array}$ & & & $\mathrm{Fa} 0 / 1$ & $\begin{array}{c}200.200 . \\
30.2\end{array}$ & $\begin{array}{l}255.255 \\
255.252\end{array}$ & $\begin{array}{c}200.200 . \\
30.1\end{array}$ \\
\hline & Eth1/3 & $\begin{array}{c}200.200 \\
40.1\end{array}$ & $\begin{array}{l}255.255 . \\
255.252\end{array}$ & & & $\mathrm{Fa} 1 / 0$ & $\begin{array}{c}100.100 . \\
20.2\end{array}$ & $\begin{array}{l}255.255 . \\
255.252\end{array}$ & \\
\hline & Eth2/0 & $\begin{array}{c}200.200 . \\
50.1\end{array}$ & $\begin{array}{l}255.255 . \\
255.252\end{array}$ & & & $\mathrm{Fa} 1 / 1$ & $\begin{array}{c}100.100 . \\
30.1\end{array}$ & $\begin{array}{l}255.255 \\
255.252\end{array}$ & \\
\hline & Eth2/1 & $\begin{array}{c}200.200 \\
60.1\end{array}$ & $\begin{array}{l}255.255 . \\
255.252\end{array}$ & & & $\mathrm{Fa} 0 / 0$ & $\begin{array}{c}172.15 .4 \\
.1\end{array}$ & $\begin{array}{c}255.255 \\
252.0\end{array}$ & \\
\hline & Eth $2 / 2$ & $\begin{array}{c}200.200 . \\
70.1\end{array}$ & $\begin{array}{l}255.255 . \\
255.252\end{array}$ & & & $\mathrm{Fa} 0 / 1$ & $\begin{array}{c}200.200 . \\
40.2\end{array}$ & $\begin{array}{l}255.255 . \\
255.252\end{array}$ & $\begin{array}{c}200.200 . \\
40.1\end{array}$ \\
\hline & Eth2/3 & $\begin{array}{c}200.200 . \\
80.1\end{array}$ & $\begin{array}{l}255.255 . \\
255.252\end{array}$ & & & $\mathrm{Fa} 1 / 0$ & $\begin{array}{c}100.100 . \\
30.2\end{array}$ & $\begin{array}{l}255.255 . \\
255.252\end{array}$ & \\
\hline & Eth3/0 & $\begin{array}{c}200.200 \\
90.1\end{array}$ & $\begin{array}{l}255.255 . \\
255.252\end{array}$ & & & $\mathrm{Fa} 1 / 1$ & $\begin{array}{c}100.100 \\
40.1\end{array}$ & $\begin{array}{l}255.255 \\
255.252\end{array}$ & \\
\hline & Eth3/1 & $\begin{array}{c}200.200 . \\
100.1\end{array}$ & $\begin{array}{l}255.255 . \\
255.252\end{array}$ & & & $\mathrm{Fa} 0 / 0$ & $\begin{array}{c}172.15 .1 \\
2.1\end{array}$ & $\begin{array}{c}255.255 \\
252.0\end{array}$ & \\
\hline & Eth3/2 & $\begin{array}{c}200.200 \\
110.1\end{array}$ & $\begin{array}{l}255.255 . \\
255.252\end{array}$ & & & $\mathrm{Fa} 0 / 1$ & $\begin{array}{c}200.200 . \\
50.2\end{array}$ & $\begin{array}{l}255.255 \\
255.252\end{array}$ & $\begin{array}{c}200.200 . \\
50.1\end{array}$ \\
\hline & Eth3/3 & $\begin{array}{c}200.200 . \\
120.1\end{array}$ & $\begin{array}{l}255.255 . \\
255.252\end{array}$ & & & $\mathrm{Fa} 1 / 0$ & $\begin{array}{c}100.100 . \\
40.2\end{array}$ & $\begin{array}{l}255.255 \\
255.252\end{array}$ & \\
\hline \multirow{3}{*}{ HUKUM } & $\mathrm{Fa} 0 / 0$ & $\begin{array}{c}172.16 .2 \\
0.1\end{array}$ & $\begin{array}{c}255.255 . \\
252.0\end{array}$ & & & $\mathrm{Fa} 1 / 1$ & $\begin{array}{c}100.100 . \\
50.1\end{array}$ & $\begin{array}{l}255.255 \\
255.252\end{array}$ & \\
\hline & $\mathrm{Fa} 0 / 1$ & $\begin{array}{c}200.200 \\
10.2\end{array}$ & $\begin{array}{l}255.255 . \\
255.252\end{array}$ & $\begin{array}{c}200.200 \\
10.1\end{array}$ & \multirow{4}{*}{ FAI } & $\mathrm{Fa} 0 / 0$ & $\begin{array}{c}172.15 .8 \\
.1\end{array}$ & $\begin{array}{c}255.255 \\
252.0\end{array}$ & \\
\hline & $\mathrm{Fa} 1 / 0$ & $\begin{array}{c}100.100 . \\
10.1\end{array}$ & $\begin{array}{l}255.255 . \\
255.252\end{array}$ & & & $\mathrm{Fa} 0 / 1$ & $\begin{array}{c}200.200 . \\
60.2\end{array}$ & $\begin{array}{l}255.255 \\
255.252\end{array}$ & $\begin{array}{c}200.200 . \\
60.1\end{array}$ \\
\hline \multirow{4}{*}{ FISIPOL } & $\mathrm{Fa} 0 / 0$ & $\begin{array}{c}172.16 .2 \\
4.1\end{array}$ & $\begin{array}{c}255.255 . \\
252.0\end{array}$ & & & $\mathrm{Fa} 1 / 0$ & $\begin{array}{c}100.100 . \\
50.2\end{array}$ & $\begin{array}{l}255.255 . \\
255.252\end{array}$ & \\
\hline & $\mathrm{Fa} 0 / 1$ & $\begin{array}{c}200.200 . \\
20.2\end{array}$ & $\begin{array}{l}255.255 . \\
255.252\end{array}$ & $\begin{array}{c}200.200 \\
20.1\end{array}$ & & $\mathrm{Fa} 1 / 1$ & $\begin{array}{c}100.100 \\
60.1\end{array}$ & $\begin{array}{l}255.255 . \\
255.252\end{array}$ & \\
\hline & $\mathrm{Fa} 1 / 0$ & $\begin{array}{c}100.100 . \\
10.2\end{array}$ & $\begin{array}{l}255.255 . \\
255.252\end{array}$ & & \multirow{3}{*}{ PERTANIAN } & $\mathrm{Fa} 0 / 0$ & $\begin{array}{c}172.20 .2 \\
0.1\end{array}$ & $\begin{array}{c}255.255 . \\
252.0\end{array}$ & \\
\hline & $\mathrm{Fa} 1 / 1$ & $\begin{array}{c}100.100 . \\
20.1\end{array}$ & $\begin{array}{l}255.255 . \\
255.252\end{array}$ & & & $\mathrm{Fa} 0 / 1$ & $\begin{array}{c}200.200 . \\
70.2\end{array}$ & $\begin{array}{l}255.255 \\
255.252\end{array}$ & $\begin{array}{c}200.200 . \\
70.1\end{array}$ \\
\hline FKIP & $\mathrm{Fa} 0 / 0$ & $\begin{array}{c}172.16 .2 \\
8.1\end{array}$ & $\begin{array}{c}255.255 . \\
252.0\end{array}$ & & & $\mathrm{Fa} 1 / 0$ & $\begin{array}{c}100.100 \\
60.2\end{array}$ & $\begin{array}{l}255.255 \\
255.252\end{array}$ & \\
\hline
\end{tabular}


Syukur, A. dan Julianti, L., Simulasi Pemanfaatan Dynamic Routing ... 27

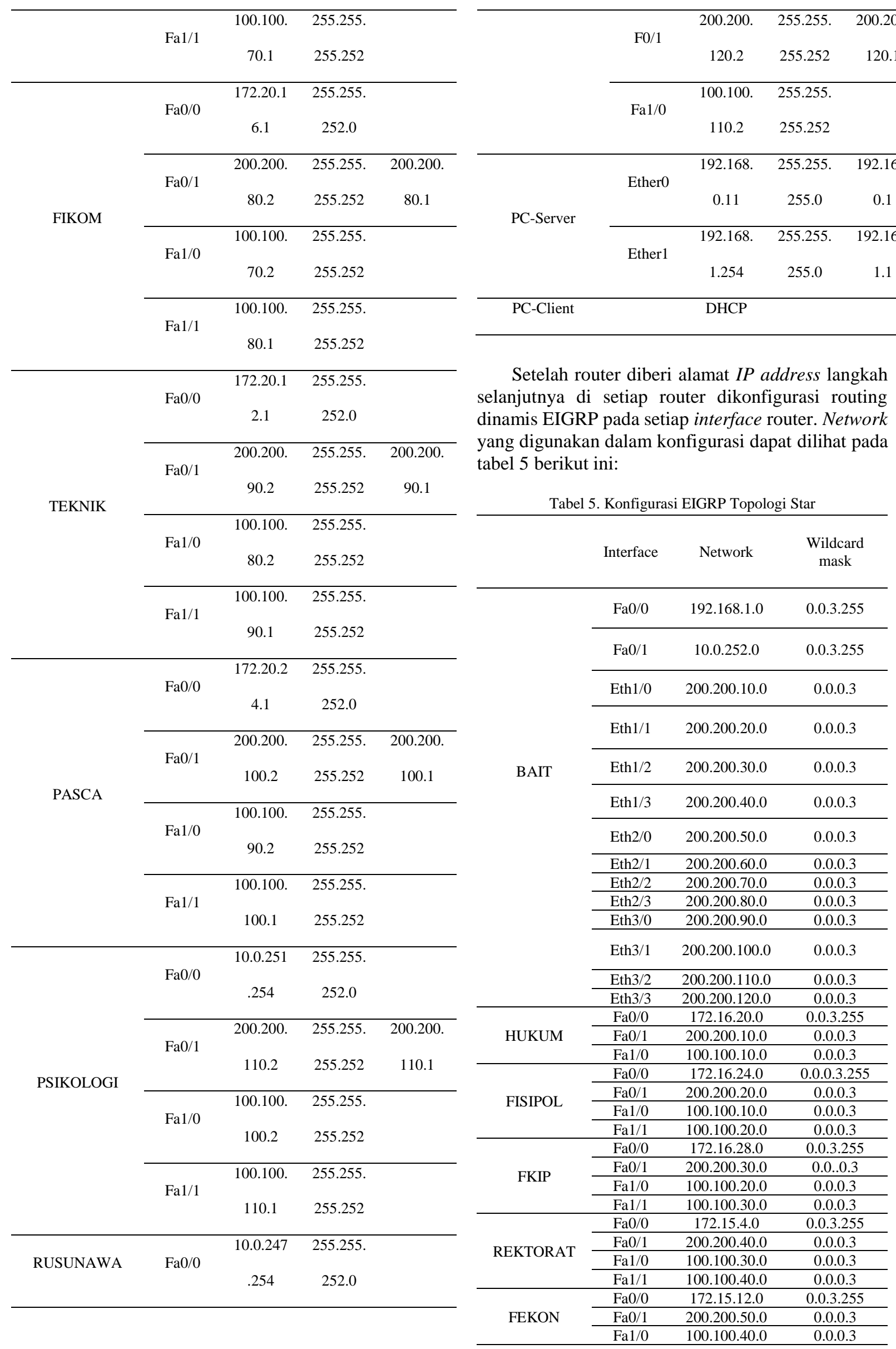


28 Jurnal Teknologi Informasi dan Ilmu Komputer (JTIIK), Vol. 5, No.1, Maret 2018, hlm. 23-34

\begin{tabular}{|c|c|c|c|}
\hline & $\mathrm{Fa} 1 / 1$ & 100.100 .50 .0 & 0.0 .0 .3 \\
\hline \multirow{4}{*}{ FAI } & $\mathrm{Fa} 0 / 0$ & 172.15 .8 .0 & 0.0 .3 .255 \\
\hline & $\mathrm{Fa} 0 / 1$ & 200.200 .60 .0 & 0.0 .0 .3 \\
\hline & $\mathrm{Fa} 1 / 0$ & 100.100 .50 .0 & 0.0 .0 .3 \\
\hline & $\mathrm{Fa} 1 / 1$ & 100.100 .60 .0 & 0.0 .0 .3 \\
\hline \multirow{4}{*}{ PERTANIAN } & $\mathrm{Fa} 0 / 0$ & 172.20 .20 .0 & 0.0 .3 .255 \\
\hline & $\mathrm{Fa} 0 / 1$ & 200.200 .70 .0 & 0.0 .0 .3 \\
\hline & $\mathrm{Fa} 1 / 0$ & 100.100 .60 .0 & 0.0 .0 .3 \\
\hline & $\mathrm{Fa} 1 / 1$ & 100.100 .70 .0 & 0.0 .0 .3 \\
\hline \multirow{4}{*}{ FIKOM } & $\mathrm{Fa} 0 / 0$ & 172.20 .16 .0 & 0.0 .3 .255 \\
\hline & $\mathrm{Fa} 0 / 1$ & 200.200 .80 .0 & 0.0 .0 .3 \\
\hline & $\mathrm{Fa} 1 / 0$ & 100.100 .70 .0 & 0.0 .0 .3 \\
\hline & $\mathrm{Fa} 1 / 1$ & 100.100 .80 .0 & 0.0 .0 .3 \\
\hline \multirow{4}{*}{ TEKNIK } & $\mathrm{Fa} 0 / 0$ & 172.20 .12 .0 & 0.0 .3 .255 \\
\hline & $\mathrm{Fa} 0 / 1$ & 200.200 .90 .0 & 0.0 .0 .3 \\
\hline & $\mathrm{Fa} 1 / 0$ & 100.100 .80 .0 & 0.0 .0 .3 \\
\hline & $\mathrm{Fa} 1 / 1$ & 100.100 .90 .0 & 0.0 .0 .3 \\
\hline \multirow{4}{*}{ PASCA } & $\mathrm{Fa} 0 / 0$ & 172.20 .24 .0 & 0.0 .3 .255 \\
\hline & $\mathrm{Fa} 0 / 1$ & 200.200 .100 .0 & 0.0 .0 .3 \\
\hline & $\mathrm{Fa} 1 / 0$ & 100.100 .90 .0 & 0.0 .0 .3 \\
\hline & $\mathrm{Fa} 1 / 1$ & 100.100 .100 .0 & 0.0 .0 .3 \\
\hline \multirow{4}{*}{ PSIKOLOGI } & $\mathrm{Fa} 0 / 0$ & 10.0 .248 .0 & 0.0 .3 .255 \\
\hline & $\mathrm{Fa} 0 / 1$ & 200.200 .110 .0 & 0.0 .0 .3 \\
\hline & $\mathrm{Fa} 1 / 0$ & 100.100 .100 .0 & 0.0 .0 .3 \\
\hline & $\mathrm{Fa} 1 / 1$ & 100.100 .110 .0 & 0.0 .0 .3 \\
\hline \multirow{3}{*}{ RUSUNAWA } & $\mathrm{Fa} 0 / 0$ & 10.0 .244 .0 & 0.0 .3 .255 \\
\hline & $\mathrm{F} 0 / 1$ & 200.200 .120 .0 & 0.0 .0 .3 \\
\hline & $\mathrm{Fa} 1 / 0$ & 100.100 .110 .0 & 0.0 .0 .3 \\
\hline
\end{tabular}

Pada rancangan ini menggambarkan topologi ring yang akan dibuat nanti pada GNS3 dengan skenario jalur dan IP address yang sudah ditentukan pada tabel 6 dibawah ini:

Tabel 6. Address Topologi Ring

\begin{tabular}{|c|c|c|c|c|}
\hline & $\begin{array}{l}\text { Interf } \\
\text { ace }\end{array}$ & $\begin{array}{c}\text { IP } \\
\text { Address }\end{array}$ & $\begin{array}{l}\text { Subnet } \\
\text { Mask }\end{array}$ & Gateway \\
\hline \multirow{2}{*}{ GATEWAY } & $\mathrm{Fa} 0 / 0$ & $\begin{array}{c}192.168 . \\
137.2\end{array}$ & $\begin{array}{c}255.255 . \\
255.0\end{array}$ & $\begin{array}{c}192.168 .13 \\
7.1\end{array}$ \\
\hline & $\mathrm{Fa} 0 / 1$ & $\begin{array}{c}192.168 . \\
0.1\end{array}$ & $\begin{array}{c}255.255 . \\
255.0 \\
\end{array}$ & \\
\hline \multirow{4}{*}{ BAIT } & $\mathrm{Fa} 0 / 0$ & $\begin{array}{c}192.168 . \\
1.1 \\
\end{array}$ & $\begin{array}{c}255.255 . \\
255.0 \\
\end{array}$ & $\begin{array}{c}192.168 .1 .2 \\
54 \\
\end{array}$ \\
\hline & $\mathrm{Fa} 0 / 1$ & $\begin{array}{c}10.0 .255 \\
.254 \\
\end{array}$ & $\begin{array}{c}255.255 . \\
252.0 \\
\end{array}$ & \\
\hline & $\mathrm{Fa} 1 / 0$ & $\begin{array}{c}100.100 . \\
10.1\end{array}$ & $\begin{array}{l}255.255 . \\
255.252 \\
\end{array}$ & \\
\hline & $\mathrm{Fa} 1 / 1$ & $\begin{array}{c}100.100 . \\
130.1\end{array}$ & $\begin{array}{l}255.255 . \\
255.252\end{array}$ & $\begin{array}{c}100.100 .13 \\
0.2\end{array}$ \\
\hline \multirow{3}{*}{ HUKUM } & $\mathrm{Fa} 0 / 0$ & $\begin{array}{c}172.16 .2 \\
0.1\end{array}$ & $\begin{array}{c}255.255 . \\
252.0\end{array}$ & \\
\hline & $\mathrm{Fa} 0 / 1$ & $\begin{array}{c}200.200 \\
10.2 \\
\end{array}$ & $\begin{array}{l}255.255 . \\
255.252 \\
\end{array}$ & $\begin{array}{c}100.100 .10 . \\
1\end{array}$ \\
\hline & $\mathrm{Fa} 1 / 0$ & $\begin{array}{c}100.100 . \\
20.1 \\
\end{array}$ & $\begin{array}{l}255.255 . \\
255.252 \\
\end{array}$ & \\
\hline \multirow{3}{*}{ FISIPOL } & $\mathrm{Fa} 0 / 0$ & $\begin{array}{c}172.16 .2 \\
4.1\end{array}$ & $\begin{array}{c}255.255 . \\
252.0\end{array}$ & \\
\hline & $\mathrm{Fa} 0 / 1$ & $\begin{array}{c}100.100 . \\
20.2\end{array}$ & $\begin{array}{l}255.255 . \\
255.252\end{array}$ & \\
\hline & $\mathrm{Fa} 1 / 0$ & $\begin{array}{c}100.100 . \\
30.1\end{array}$ & $\begin{array}{l}255.255 . \\
255.252\end{array}$ & $\begin{array}{c}100.100 .20 \\
1\end{array}$ \\
\hline \multirow{3}{*}{ FKIP } & $\mathrm{Fa} 0 / 0$ & $\begin{array}{c}172.16 .2 \\
8.1 \\
\end{array}$ & $\begin{array}{c}255.255 . \\
252.0 \\
\end{array}$ & \\
\hline & $\mathrm{Fa} 0 / 1$ & $\begin{array}{c}100.100 . \\
30.2\end{array}$ & $\begin{array}{l}255.255 . \\
255.252\end{array}$ & \\
\hline & $\mathrm{Fa} 1 / 0$ & $\begin{array}{c}100.100 . \\
40.1\end{array}$ & $\begin{array}{l}255.255 . \\
255.252\end{array}$ & $\begin{array}{c}100.100 .30 \\
1\end{array}$ \\
\hline
\end{tabular}

\begin{tabular}{|c|c|c|c|c|}
\hline \multirow{3}{*}{ REKTORAT } & $\mathrm{Fa} 0 / 0$ & $\begin{array}{c}172.15 .4 \\
.1\end{array}$ & $\begin{array}{c}255.255 . \\
252.0\end{array}$ & \\
\hline & $\mathrm{Fa} 0 / 1$ & $\begin{array}{c}100.100 . \\
40.2\end{array}$ & $\begin{array}{l}255.255 . \\
255.252\end{array}$ & \\
\hline & $\mathrm{Fa} 1 / 0$ & $\begin{array}{c}100.100 . \\
50.1\end{array}$ & $\begin{array}{l}255.255 . \\
255.252 \\
\end{array}$ & $\begin{array}{c}100.100 .40 . \\
1\end{array}$ \\
\hline \multirow{3}{*}{ FEKON } & $\mathrm{Fa} 0 / 0$ & $\begin{array}{c}172.15 .1 \\
2.1 \\
\end{array}$ & $\begin{array}{c}255.255 . \\
252.0 \\
\end{array}$ & \\
\hline & $\mathrm{Fa} 0 / 1$ & $\begin{array}{c}100.100 . \\
50.2 \\
\end{array}$ & $\begin{array}{l}255.255 . \\
255.252 \\
\end{array}$ & \\
\hline & $\mathrm{Fa} 1 / 0$ & $\begin{array}{c}100.100 . \\
60.1\end{array}$ & $\begin{array}{l}255.255 . \\
255.252\end{array}$ & $\begin{array}{c}100.100 .50 \\
1\end{array}$ \\
\hline \multirow{3}{*}{ FAI } & $\mathrm{Fa} 0 / 0$ & $\begin{array}{c}172.15 .8 \\
.1 \\
\end{array}$ & $\begin{array}{c}255.255 . \\
252.0\end{array}$ & \\
\hline & $\mathrm{Fa} 0 / 1$ & $\begin{array}{c}100.100 . \\
60.2 \\
\end{array}$ & $\begin{array}{l}255.255 . \\
255.252 \\
\end{array}$ & \\
\hline & $\mathrm{Fa} 1 / 0$ & $\begin{array}{c}100.100 . \\
70.1 \\
\end{array}$ & $\begin{array}{l}255.255 . \\
255.252 \\
\end{array}$ & $\begin{array}{c}100.100 .60 . \\
1\end{array}$ \\
\hline \multirow{3}{*}{$\begin{array}{c}\text { PERTANIA } \\
\mathrm{N}\end{array}$} & $\mathrm{Fa} 0 / 0$ & $\begin{array}{c}172.20 .2 \\
0.1\end{array}$ & $\begin{array}{c}255.255 . \\
252.0\end{array}$ & \\
\hline & $\mathrm{Fa} 0 / 1$ & $\begin{array}{c}100.100 . \\
70.2\end{array}$ & $\begin{array}{l}255.255 . \\
255.252\end{array}$ & \\
\hline & $\mathrm{Fa} 1 / 0$ & $\begin{array}{c}100.100 . \\
80.1\end{array}$ & $\begin{array}{l}255.255 . \\
255.252\end{array}$ & $\begin{array}{c}100.100 .70 . \\
1\end{array}$ \\
\hline \multirow{3}{*}{ FIKOM } & $\mathrm{Fa} 0 / 0$ & $\begin{array}{c}172.20 .1 \\
6.1 \\
\end{array}$ & $\begin{array}{c}255.255 . \\
252.0\end{array}$ & \\
\hline & $\mathrm{Fa} 0 / 1$ & $\begin{array}{c}100.100 . \\
80.2 \\
\end{array}$ & $\begin{array}{l}255.255 . \\
255.252 \\
\end{array}$ & \\
\hline & $\mathrm{Fa} 1 / 0$ & $\begin{array}{c}100.100 . \\
90.1\end{array}$ & $\begin{array}{l}255.255 . \\
255.252\end{array}$ & $\begin{array}{c}100.100 .80 \\
1\end{array}$ \\
\hline \multirow{3}{*}{ TEKNIK } & $\mathrm{Fa} 0 / 0$ & $\begin{array}{c}172.20 .1 \\
2.1\end{array}$ & $\begin{array}{c}255.255 . \\
252.0\end{array}$ & \\
\hline & $\mathrm{Fa} 0 / 1$ & $\begin{array}{c}100.100 . \\
90.2\end{array}$ & $\begin{array}{l}255.255 . \\
255.252 \\
\end{array}$ & \\
\hline & $\mathrm{Fa} 1 / 0$ & $\begin{array}{c}100.100 . \\
100.1\end{array}$ & $\begin{array}{l}255.255 . \\
255.252\end{array}$ & $\begin{array}{c}100.100 .90 . \\
1\end{array}$ \\
\hline \multirow{3}{*}{ PASCA } & $\mathrm{Fa} 0 / 0$ & $\begin{array}{c}172.20 .2 \\
4.1 \\
\end{array}$ & $\begin{array}{c}255.255 . \\
252.0 \\
\end{array}$ & \\
\hline & $\mathrm{Fa} 0 / 1$ & $\begin{array}{c}100.100 . \\
100.2\end{array}$ & $\begin{array}{l}255.255 . \\
255.252\end{array}$ & \\
\hline & $\mathrm{Fa} 1 / 0$ & $\begin{array}{c}100.100 . \\
110.1\end{array}$ & $\begin{array}{l}255.255 \\
255.252\end{array}$ & $\begin{array}{c}100.100 .10 \\
0.1\end{array}$ \\
\hline \multirow{3}{*}{ PSIKOLOGI } & $\mathrm{Fa} 0 / 0$ & $\begin{array}{c}10.0 .251 \\
.254 \\
\end{array}$ & $\begin{array}{c}255.255 . \\
252.0\end{array}$ & \\
\hline & $\mathrm{Fa} 0 / 1$ & $\begin{array}{c}100.100 . \\
110.2 \\
\end{array}$ & $\begin{array}{l}255.255 . \\
255.252 \\
\end{array}$ & \\
\hline & $\mathrm{Fa} 1 / 0$ & $\begin{array}{c}100.100 . \\
120.1 \\
\end{array}$ & $\begin{array}{l}255.255 . \\
255.252 \\
\end{array}$ & $\begin{array}{c}100.100 .11 \\
0.1 \\
\end{array}$ \\
\hline \multirow{3}{*}{$\begin{array}{c}\text { RUSUNAW } \\
\text { A }\end{array}$} & $\mathrm{Fa} 0 / 0$ & $\begin{array}{c}10.0 .247 \\
.254 \\
\end{array}$ & $\begin{array}{c}255.255 . \\
252.0 \\
\end{array}$ & \\
\hline & $\mathrm{Fa} 0 / 1$ & $\begin{array}{c}100.100 . \\
130.2 \\
\end{array}$ & $\begin{array}{l}255.255 . \\
255.252 \\
\end{array}$ & \\
\hline & $\mathrm{Fa} 1 / 0$ & $\begin{array}{c}100.100 . \\
120.2 \\
\end{array}$ & $\begin{array}{l}255.255 . \\
255.252 \\
\end{array}$ & \\
\hline \multirow{2}{*}{ PC-Server } & $\begin{array}{c}\text { Ether } \\
0\end{array}$ & $\begin{array}{c}192.168 . \\
0.11\end{array}$ & $\begin{array}{c}255.255 . \\
255.0\end{array}$ & 192.168.0.1 \\
\hline & $\begin{array}{c}\text { Ether } \\
1\end{array}$ & $\begin{array}{c}192.168 . \\
1.254 \\
\end{array}$ & $\begin{array}{c}255.255 . \\
255.0\end{array}$ & 192.168.1.1 \\
\hline PC-Client & & DHCP & & \\
\hline
\end{tabular}

Setelah router diberi alamat IP address langkah selanjutnya di setiap router dikonfigurasi routing dinamis EIGRP pada setiap interface router. Network yang digunakan dalam konfigurasi dapat dilihat pada tabel 7 berikut ini: 
Tabel 7. Konfigurasi EIGRP Topologi Ring

\begin{tabular}{|c|c|c|c|}
\hline & Interface & Network & Wildcard Mask \\
\hline \multirow{4}{*}{ BAIT } & $\mathrm{Fa} 0 / 0$ & 192.168 .1 .0 & 0.0 .0 .255 \\
\hline & $\mathrm{Fa} 0 / 1$ & 10.0 .252 .0 & 0.0 .3 .255 \\
\hline & $\mathrm{Fa} 1 / 0$ & 100.100 .10 .0 & 0.0 .0 .3 \\
\hline & $\mathrm{Fa} 1 / 1$ & 100.100 .130 .0 & 0.0 .0 .3 \\
\hline \multirow{3}{*}{ HUKUM } & $\mathrm{Fa} 0 / 0$ & 172.16 .20 .0 & 0.0 .3 .255 \\
\hline & $\mathrm{Fa} 0 / 1$ & 200.200 .10 .0 & 0.0 .0 .3 \\
\hline & $\mathrm{Fa} 1 / 0$ & 100.100 .20 .0 & 0.0 .0 .3 \\
\hline \multirow{3}{*}{ FISIPOL } & $\mathrm{Fa} 0 / 0$ & 172.16 .24 .0 & 0.0 .3 .255 \\
\hline & $\mathrm{Fa} 0 / 1$ & 100.100 .20 .0 & 0.0 .0 .3 \\
\hline & $\mathrm{Fa} 1 / 0$ & 100.100 .30 .0 & 0.0 .0 .3 \\
\hline \multirow{3}{*}{ FKIP } & $\mathrm{Fa} 0 / 0$ & 172.16 .28 .0 & 0.0 .3 .255 \\
\hline & $\mathrm{Fa} 0 / 1$ & 100.100 .30 .0 & 0.0 .0 .3 \\
\hline & $\mathrm{Fa} 1 / 0$ & 100.100 .40 .0 & 0.0 .0 .3 \\
\hline \multirow{3}{*}{ REKTORAT } & $\mathrm{Fa} 0 / 0$ & 172.15 .4 .0 & 0.0 .0 .3 \\
\hline & $\mathrm{Fa} 0 / 1$ & 100.100 .40 .0 & 0.0 .0 .3 \\
\hline & $\mathrm{Fa} 1 / 0$ & 100.100 .50 .0 & 0.0 .0 .3 \\
\hline \multirow{3}{*}{ FEKON } & $\mathrm{Fa} 0 / 0$ & 172.15 .12 .0 & 0.0 .3 .255 \\
\hline & $\mathrm{Fa} 0 / 1$ & 100.100 .50 .0 & 0.0 .0 .3 \\
\hline & $\mathrm{Fa} 1 / 0$ & 100.100 .60 .0 & 0.0 .0 .3 \\
\hline \multirow{3}{*}{ FAI } & $\mathrm{Fa} 0 / 0$ & 172.15 .8 .0 & 0.0 .3 .255 \\
\hline & $\mathrm{Fa} 0 / 1$ & 100.100 .60 .0 & 0.0 .0 .3 \\
\hline & $\mathrm{Fa} 1 / 0$ & 100.100 .70 .0 & 0.0 .0 .3 \\
\hline \multirow{3}{*}{ PERTANIAN } & $\mathrm{Fa} 0 / 0$ & 172.20 .20 .0 & 0.0 .3 .255 \\
\hline & $\mathrm{Fa} 0 / 1$ & 100.100 .70 .0 & 0.0 .0 .3 \\
\hline & $\mathrm{Fa} 1 / 0$ & 100.100 .80 .0 & 0.0 .0 .3 \\
\hline \multirow{3}{*}{ FIKOM } & $\mathrm{Fa} 0 / 0$ & 172.20 .16 .0 & 0.0 .3 .255 \\
\hline & $\mathrm{Fa} 0 / 1$ & 100.100 .80 .0 & 0.0 .0 .3 \\
\hline & $\mathrm{Fa} 1 / 0$ & 100.100 .90 .0 & 0.0 .0 .3 \\
\hline \multirow{3}{*}{ TEKNIK } & $\mathrm{Fa} 0 / 0$ & 172.20 .12 .0 & 0.0 .3 .255 \\
\hline & $\mathrm{Fa} 0 / 1$ & 100.100 .90 .0 & 0.0 .0 .3 \\
\hline & $\mathrm{Fa} 1 / 0$ & 100.100 .100 .0 & 0.0 .0 .3 \\
\hline \multirow{3}{*}{ PASCA } & $\mathrm{Fa} 0 / 0$ & 172.20 .24 .0 & 0.0 .3 .255 \\
\hline & $\mathrm{Fa} 0 / 1$ & 100.100 .100 .0 & 0.0 .0 .3 \\
\hline & $\mathrm{Fa} 1 / 0$ & 100.100 .110 .0 & 0.0 .0 .3 \\
\hline \multirow{3}{*}{ PSIKOLOGI } & $\mathrm{Fa} 0 / 0$ & 10.0.248.0 & 0.0 .3 .255 \\
\hline & $\mathrm{Fa} 0 / 1$ & 100.100 .110 .0 & 0.0 .0 .3 \\
\hline & $\mathrm{Fa} 1 / 0$ & 100.100 .120 .0 & 0.0 .0 .3 \\
\hline \multirow{3}{*}{ RUSUNAWA } & $\mathrm{Fa} 0 / 0$ & 10.0 .244 .0 & 0.0 .3 .255 \\
\hline & $\mathrm{Fa} 0 / 1$ & 100.100 .130 .0 & 0.0 .0 .3 \\
\hline & $\mathrm{Fa} 1 / 0$ & 100.100 .120 .0 & 0.0 .0 .3 \\
\hline
\end{tabular}

\section{Perencanaan Program Topologi Star}

Pada test simulasi jaringan topologi star ini menggunakan jaringan lokal yang terdiri dari 14 router, 15 switch yang ada pada beberapa fakultas di UIR, dengan sistem operasi Linux untuk server otentikasi jaringan dan GNS3 sebagai aplikasi simulasi jaringan. Berikut ini pada gambar 3 topologi yang akan digunakan.

\subsection{Skenario Yang Digunakan Pada Simulasi Topologi Star}

Dari topologi diatas dapat dilihat bahwa router utama berada di gedung BAIT. BAIT dapat terhubung ke semua fakultas UIR. Client yang akan terhubung ke jaringan UIR akan melewati beberapa router dari server melalui switch yang ada pada fakultas dan kemudian server akan meminta data client berupa username dan password (otentikasi), peneliti menggunakan software zeroshell dalam proses otentikasi client.

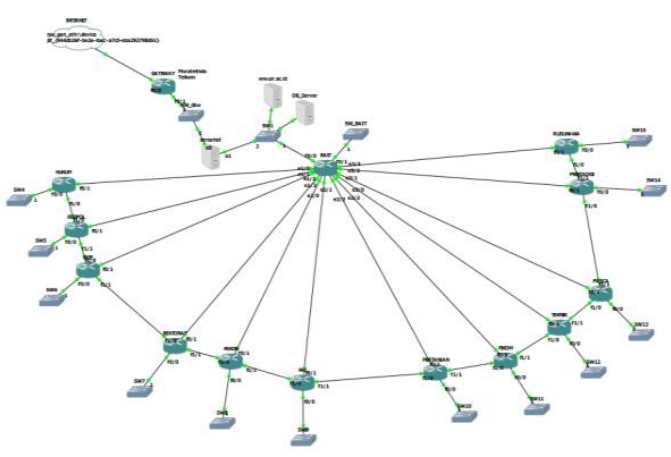

Gambar 3. Topologi Star Simulasi Jaringan EIGRP UIR

\section{Perencanaan Program Topologi Ring}

Pada test simulasi jaringan topologi ring ini menggunakan jaringan lokal yang terdiri dari 14 router, 15 switch yang ada pada beberapa fakultas di UIR. Topologi ini menggambarkan pada setiap fakultas terhubung langsung menggunakan kabel dengan fakultas tetangganya. Topologi ring UIR dapat dilihat pada gambar 4 dibawah ini:

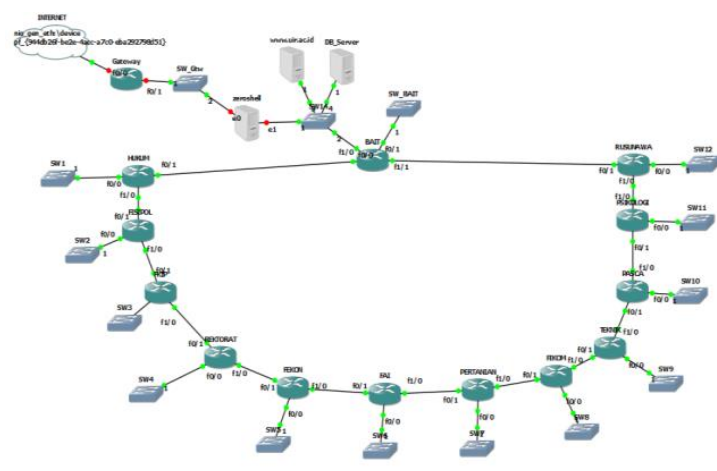

Gambar 4. Topologi Ring Simulasi Jaringan EIGRP UIR

\subsection{Skenario Yang Digunakan Pada Simulasi Topologi Ring}

Dari topologi diatas dapat dilihat bahwa router utama berada di gedung BAIT. BAIT hanya terhubung ke fakultas HUKUM dan RUSUNAWA. Client yang akan terhubung ke jaringan UIR akan melewati beberapa router dari server melalui switch yang ada pada fakultas.

\section{Pengujian Sistem}

Pada jaringan internal UIR, terdapat beberapa router yang terhubung dengan router BAIT. Setiap router tersebut memiliki jalur cadangan ke router lain untuk menuju ke BAIT. Sehingga apabila jalur utama bermasalah (yang terhubung dengan BAIT), BAIT tetap dapat dicapai.

Pada penelitian ini akan bahas tentang QoS (Quality Of Service) Throughput dan Delay dengan protocol EIGRP dalam pengiriman paket, paket yang dikirim berupa Ping ke Router, dan juga memberikan otentikasi jaringan pada saat jaringan akan di akses oleh user. 


\section{Penelusuran Jalur Yang Dilewati 10.1 Topologi Star}

Berikut ini adalah pengujian penelusuran jalur dari beberapa router menuju ke BAIT.

\section{FISIPOL}

Pada saat melakukan Ping dari PC FISIPOL ke router BAIT, tanpa adanya gangguan jaringan, maka jalur (path) yang dilalui dapat dilihat pada gambar 5 dibawah ini.

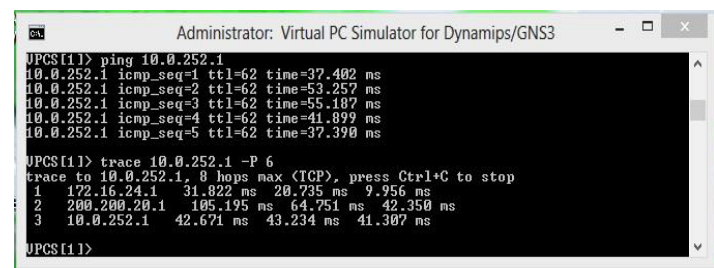

Gambar 5. Penelusuran jalur dari FISIPOL ke BAIT

Pada router FISIPOL, bila jalur utama terputus (interface f0/1), maka router akan meneruskan paket menuju router FKIP. Hal tersebut dapat dilihat pada gambar 6 berikut ini.

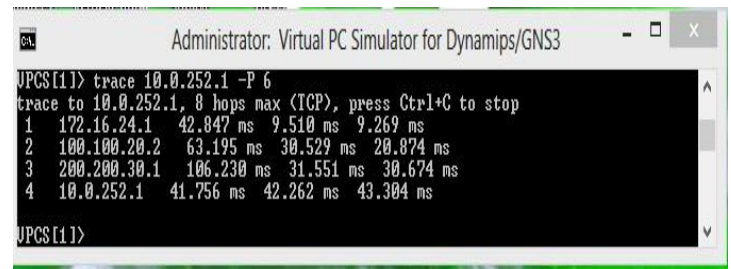

Gambar 6. Penelusuran jalur dari FISIPOL ke BAIT dengan keadaan jalur utama down

\section{Teknik}

Pada saat melakukan Ping dari PC Teknik ke router BAIT, tanpa adanya gangguan jaringan, maka jalur (path) yang dilalui dapat dilihat pada gambar 7 dibawah ini.

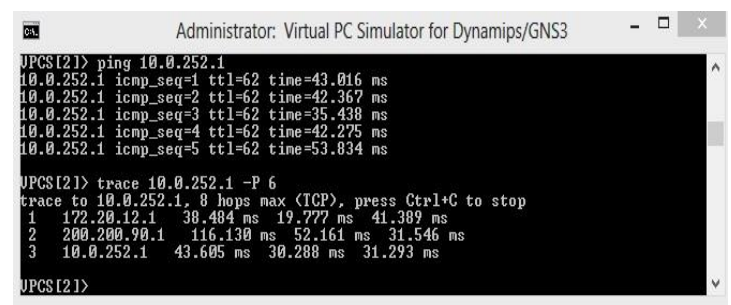

Gambar 7. Penelusuran jalur dari Teknik ke BAIT

Pada router Teknik, bila jalur utama terputus (interface f0/1), maka router akan meneruskan paket menuju router Pasca. Hal tersebut dapat dilihat pada gambar 8 berikut ini.

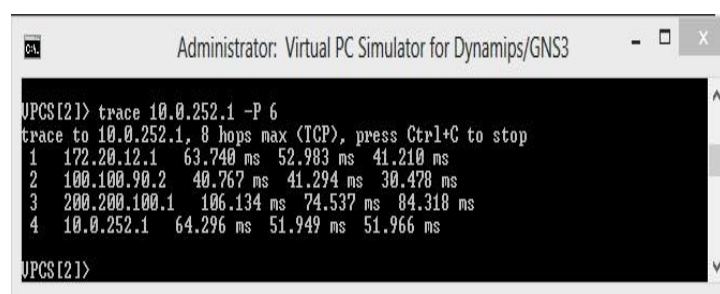

Gambar 8. Penelusuran jalur dari Teknik ke BAIT dengan keadaan jalur utama down

\section{Psikologi}

Pada saat melakukan Ping dari PC Psikologi ke router BAIT, tanpa adanya gangguan jaringan, maka jalur (path) yang dilalui dapat dilihat pada gambar 9 dibawah ini.

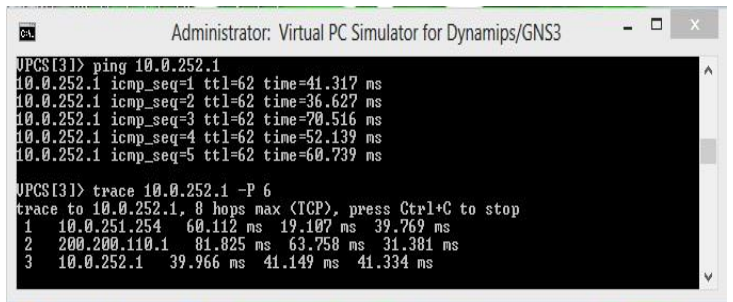

Gambar 9. Penelusuran jalur dari Psikologi ke BAIT

Pada router Psikologi, bila jalur utama terputus (interface f0/1), maka router akan meneruskan paket menuju router Pasca. Hal tersebut dapat dilihat pada gambar 10 berikut ini.

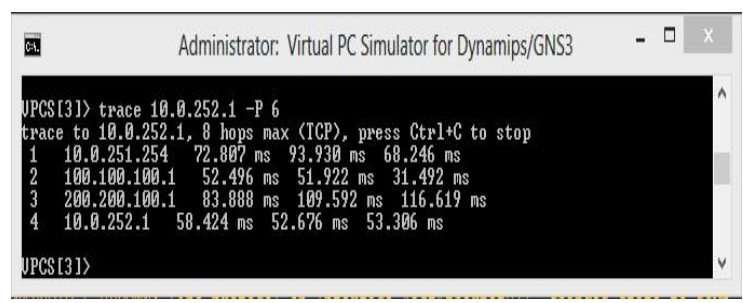

Gambar 10. Penelusuran jalur dari Psikologi ke BAIT dimana jalur utama down

\subsection{Topologi Ring}

Berikut ini adalah pengujian penelusuran jalur dari beberapa router menuju ke BAIT.

1. FISIPOL

Pada saat melakukan Ping dari PC FISIPOL ke router BAIT, tanpa adanya gangguan jaringan, maka jalur (path) yang dilalui dapat dilihat pada gambar 11 dibawah ini.

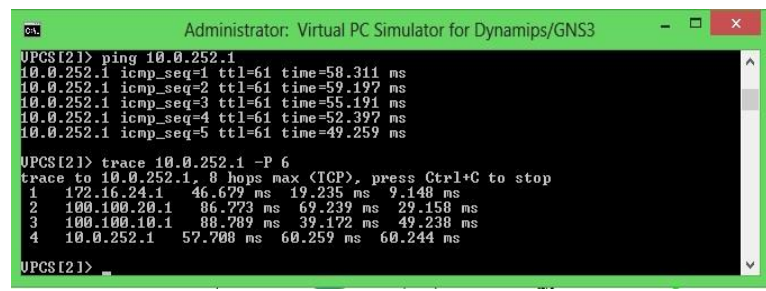

Gambar 11. Penelusuran jalur dari FISIPOL ke BAIT 
Pada router FISIPOL, bila jalur utama terputus (interface BAIT) maka router tidak akan bisa mengirimkan paket ke alamat tujuan. Hal tersebut dapat dilihat pada gambar 12 berikut ini.

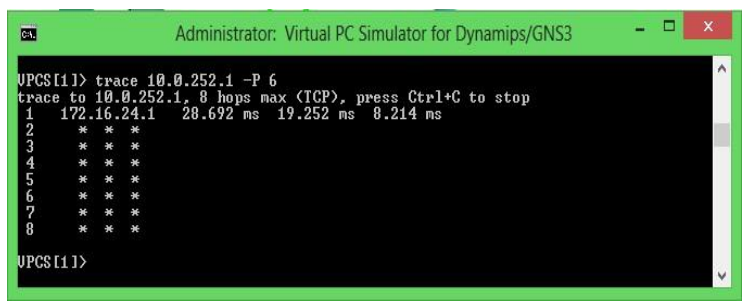

Gambar 12. Penelusuran jalur dari FISIPOL ke BAIT dengan keadaan jalur utama down

\section{Teknik}

Pada saat melakukan Ping dari PC Teknik ke router BAIT, tanpa adanya gangguan jaringan, maka jalur (path) yang dilalui dapat dilihat pada gambar 13 dibawah ini.

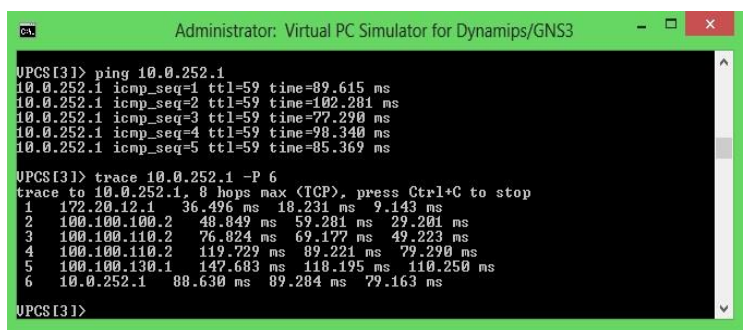

Gambar 13. Penelusuran jalur dari Teknik ke BAIT

Pada router Teknik, bila jalur utama terputus (interface BAIT) maka router tidak akan bisa mengirimkan paket ke alamat tujuan. Hal tersebut dapat dilihat pada gambar 14 berikut ini.

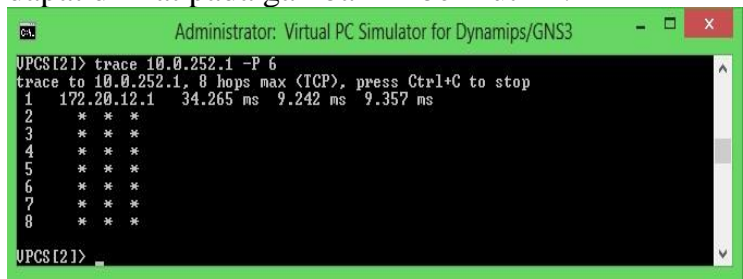

Gambar 14. Penelusuran jalur dari Teknik ke BAIT dengan jalur utama down

3. Psikologi

Pada saat melakukan Ping dari PC Psikologi ke router BAIT, tanpa adanya gangguan jaringan, maka jalur (path) yang dilalui dapat dilihat pada gambar 15 dibawah ini.

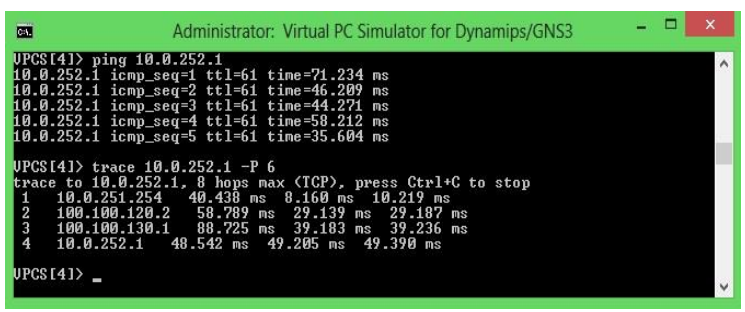

Gambar 15. Penelusuran jalur dari Psikologi ke BAIT
Pada router Psikologi, bila jalur utama terputus (interface BAIT) maka router tidak akan bisa mengirimkan paket ke alamat tujuan. Hal tersebut dapat dilihat pada gambar 16 berikut ini.

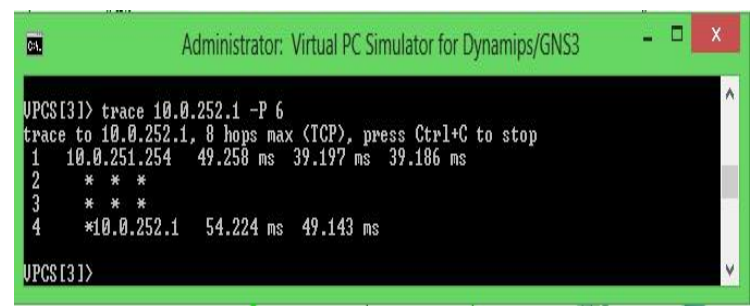

Gambar 16. Penelusuran jalur dari Psikologi ke BAIT dengan jalur utama down

Pada gambar 16. merupakan informasi jalur (path) yang tidak bisa dilewati oleh router Psikologi, ini karena topologi ring yang berbentuk cincin hanya memiliki satu kabel penghubung ke router tetangga, sehingga jika ada satu interface yang terganggu maka tidak ada jalur alternative untuk meneruskan paket ke alamat tujuan.

\section{Hasil Pengujian Throughput FISIPOL-BAIT 1-5}

Setelah hasil di dapat oleh capture wireshark hasil throughput pengujian dari PC FISIPOL menuju router BAIT dirangkum pada tabel 8 sebagai berikut.

Tabel 8. Pengujian throughput FISIPOL-BAIT 1-5

\begin{tabular}{cccc}
\hline No & $\begin{array}{c}\text { Jumlah Data } \\
\text { Yang Dikirim }\end{array}$ & $\begin{array}{c}\text { Waktu Pengiriman } \\
\text { Data }\end{array}$ & Throughput \\
\hline 1 & 46310 bytes & 26.704 second & $0.014 \mathrm{~ms}$ \\
\hline 2 & 42947 bytes & 12.839 second & $0.027 \mathrm{~ms}$ \\
\hline 3 & 34857 bytes & 17.634 second & $0.016 \mathrm{~ms}$ \\
\hline 4 & 33266 bytes & 17.850 second & $0.015 \mathrm{~ms}$ \\
\hline 5 & 20195 bytes & 15.528 second & $0.010 \mathrm{~ms}$ \\
\hline
\end{tabular}

Tabel 9. Pengujian throughput Teknik-BAIT 1-5

\begin{tabular}{cccc}
\hline No & $\begin{array}{c}\text { Jumlah Data } \\
\text { Yang Dikirim }\end{array}$ & $\begin{array}{c}\text { Waktu Pengiriman } \\
\text { Data }\end{array}$ & Throughput \\
\hline 1 & 53101 bytes & 21.513 second & $0.020 \mathrm{~ms}$ \\
\hline 2 & 46287 bytes & 16.043 second & $0.023 \mathrm{~ms}$ \\
\hline 3 & 64457 bytes & 14.428 second & $0.036 \mathrm{~ms}$ \\
\hline 4 & 27726 bytes & 15.137 second & $0.015 \mathrm{~ms}$ \\
\hline 5 & 17810 bytes & 13.015 second & $0.011 \mathrm{~ms}$ \\
\hline
\end{tabular}

Dari tabel 8 dan tabel 9 diatas dapat dijelaskan bahwa grafik nilai rata-rata throughput yang dihasilkan menunjukkan perbedaan hasil throughput yang signifikan antara uji coba pertama sampai uji coba kelima. Hal ini terjadi karena kondisi jaringan yang bisa berbeda pada saat melakukan Ping. Perbedaan data pengujian throughput FISIPOL dan Teknik dapat dilihat pada gambar grafik 17 dibawah ini. 


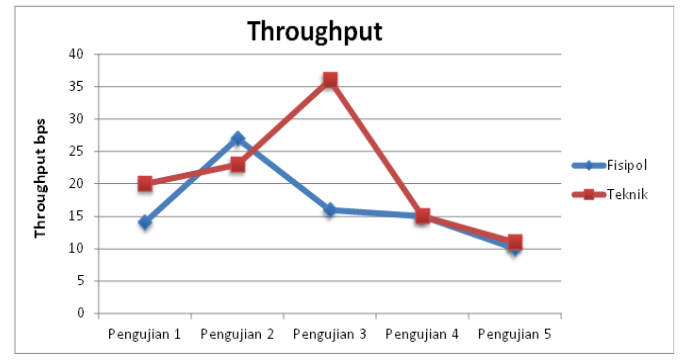

Gambar 17. Grafik Hasil Pengujian throughput FISIPOL dan Teknik

\section{Hasil Pengujian Delay FISIPOL-BAIT 1-5}

Setelah hasil di dapat oleh capture wireshark hasil delay dirangkum pada tabel 10 sebagai berikut

Tabel 10. Pengujian delay FISIPOL-BAIT 1-5

\begin{tabular}{cccc}
\hline No & $\begin{array}{c}\text { Waktu paket } \\
\text { diterima }\end{array}$ & Total paket dikirim & Delay \\
\hline \multirow{2}{*}{1} & $\begin{array}{c}21.712819000 \\
\text { seconds }\end{array}$ & $\begin{array}{c}20.659973000 \\
\text { seconds }\end{array}$ & $\begin{array}{c}1.052846 \\
\text { seconds }\end{array}$ \\
\hline \multirow{2}{*}{2} & 20.254417000 & 19.214724000 & 1.039693 \\
& seconds & seconds & seconds \\
\hline \multirow{2}{*}{3} & 7.798164000 & 6.757474000 & 1.04069 \\
& seconds & seconds & seconds \\
\hline \multirow{2}{*}{4} & 15.447229000 & 14.398529000 & 1.0487 \\
& seconds & seconds & seconds \\
\hline \multirow{2}{*}{5} & 17.726737000 & 16.675039000 & 1.051698 \\
& seconds & seconds & seconds \\
\hline
\end{tabular}

\begin{tabular}{cccc}
\multicolumn{5}{c}{ Tabel 11. Pengujian delay Teknik-BAIT 1-5 } \\
\hline No & $\begin{array}{c}\text { Waktu paket } \\
\text { diterima }\end{array}$ & Total paket dikirim & Delay \\
& 14.896301000 & 13.840515000 & 1.055786 \\
seconds & seconds & seconds \\
\hline 1 & 15.196420000 & 14.141608000 & 1.054812 \\
& seconds & seconds & seconds \\
\hline 3 & 12.543287000 & 11.502157000 & 1.04113 \\
& seconds & seconds & seconds \\
\hline 4 & 15.597217000 & 14.544368000 & 1.052849 \\
& seconds & seconds & seconds \\
\hline 5 & 11.740682000 & 10.664373000 & 1.076309 \\
& seconds & seconds & seconds \\
\hline
\end{tabular}

Dari tabel 10 dan tabel 11 diatas dapat dijelaskan bahwa grafik nilai rata-rata delay yang dihasilkan menunjukkan perbedaan hasil delay yang tidak signifikan antara uji coba pertama sampai uji coba kelima. Hal ini terjadi karena hanya simulasi hanya melakukan Ping dari PC ke Router BAIT. Perbedaan data pengujian delay FISIPOL dan delay Teknik dapat dilihat pada gambar 18 grafik dibawah ini.

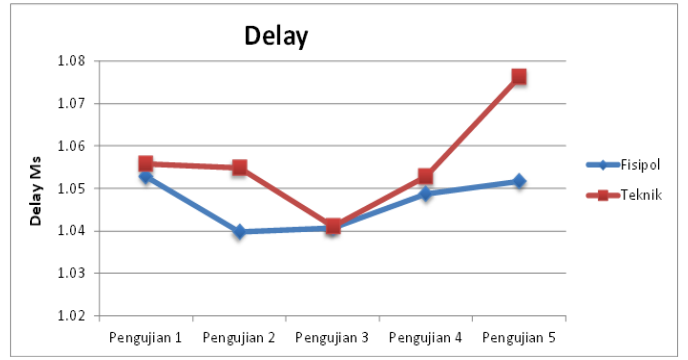

Gambar 18. Grafik Hasil Pengujian delay FISIPOL dan Teknik

\section{Otentikasi Jaringan Menggunakan Zeroshell}

Keamanan jaringan dalam proses otentikasi user dibutuhkan agar setiap user dikenali oleh jaringan. Disini penulis menggunakan software zeroshell dalam proses otentikasi jaringan. Zeroshell mengunakan radius dalam proses otentikasi, dimana radius sudah terpasang di dalam zeroshell. Cisco bisa mendukung untuk proses otentikasi jarinngan menggunakan zeroshell. Berikut ini adalah tampilan $\log$ in admin jaringan seperti pada gambar 19 dibawah ini.

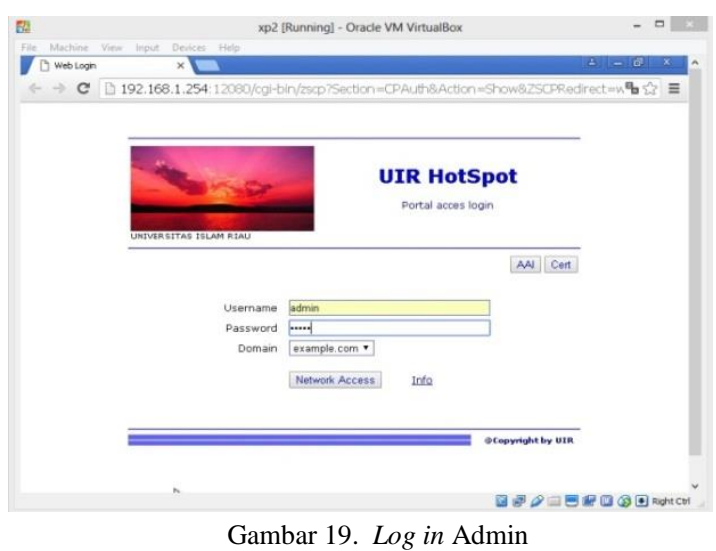

Pada Gambar 19 diatas merupakan halaman $\log$ in menggunakan zeroshell, dengan memasukkan username dan password dan kemudian klik tombol network access atau bisa dengan menekan enter pada keyboard.. Jika sukses dalam proses otentikasi maka bisa dilihat pada gambar 20 berikut ini.

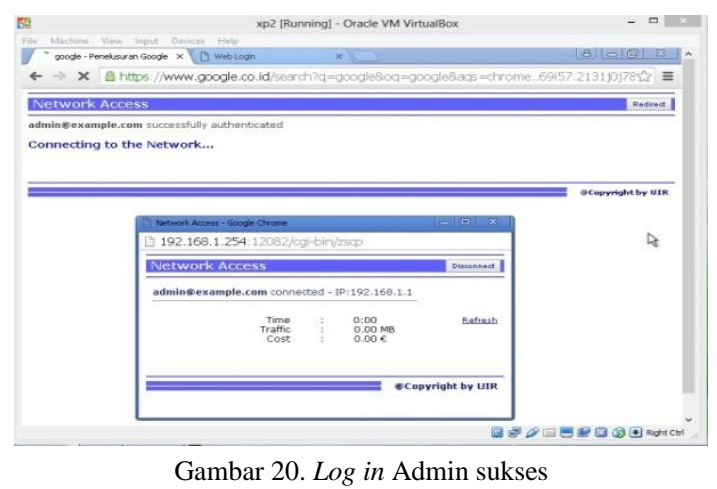


Gambar 20 diatas menunjukkan bahwa admin telah berhasil melakukan otentikasi jaringan. Selanjutnya admin bisa mengunjungi IP zeroshell untuk melihat atau mengubah data pada Zeroshell. Menu utama zeroshell dapat dilihat pada gambar 21 dibawah ini.

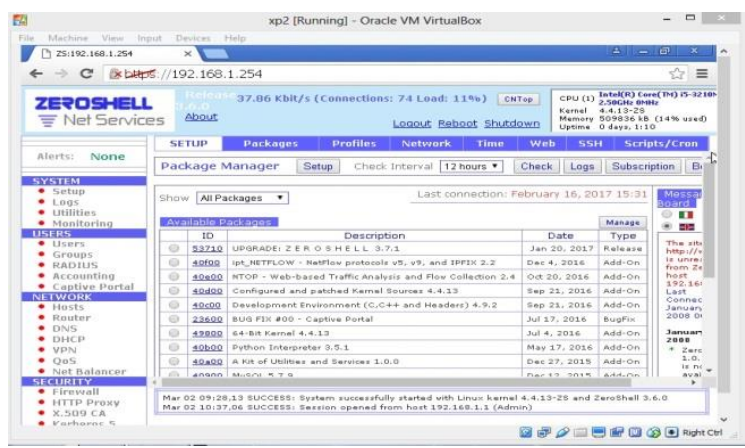

Gambar 21. Menu utama Admin zeroshell

Gambar 21 diatas merupakan menu utama admin dalam zeroshell, dimana admin bisa mengatur data yang perlu untuk otentikasi jaringan. Seperti pada gambar 22 berikut ini admin bisa menambahkan user baru ataupun mengganti password user.

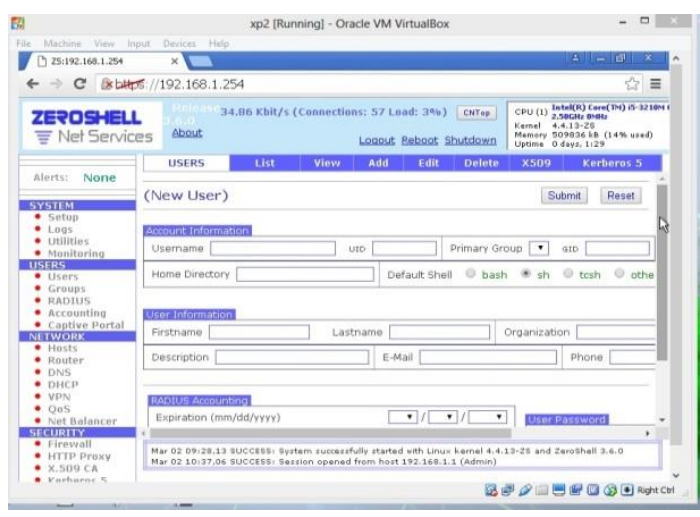

Gambar 22. Menambahkan user

Pada gambar 22 merupakan halaman untuk menambahkan user ataupun merubah password user. Untuk menambahkan user dengan cara mengisi data username, firstname, lastname, organization, description, E-Mail, phone, dan password user.

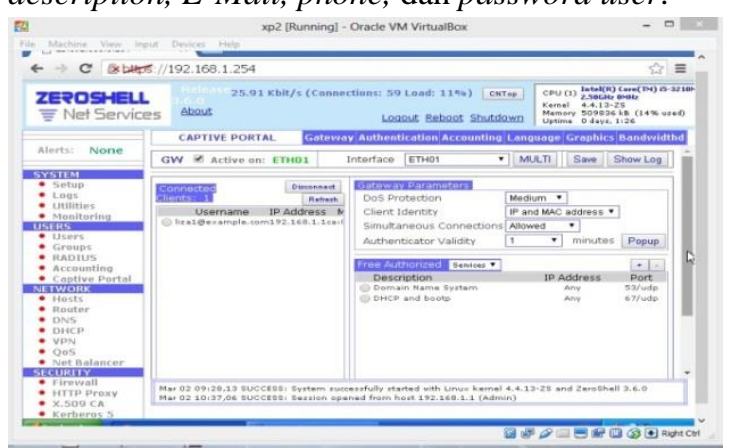

Gambar 23. Captive Portal pada gambar 23 diatas admin berada pada halaman Captive Portal, dimana pada halaman ini admin bisa melihat siapa saja user yang sedang log in. pada halaman ini admin bisa melakukan tindakan terhadap user yang sedang log in, misalnya admin bisa mematikan koneksi internet dari user.

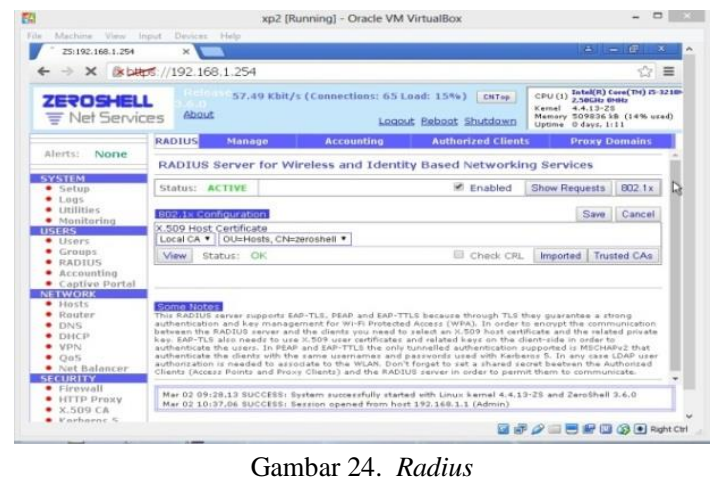

Pada gambar 24 diatas menu radius untuk admin. Radius sudah terpasang otomatis di zeroshell sehingga tidak perlu lagi melakukan install radius. Radius Server menyediakan otentikasi aman dan manajemen otomatis dari kunci enkripsi.

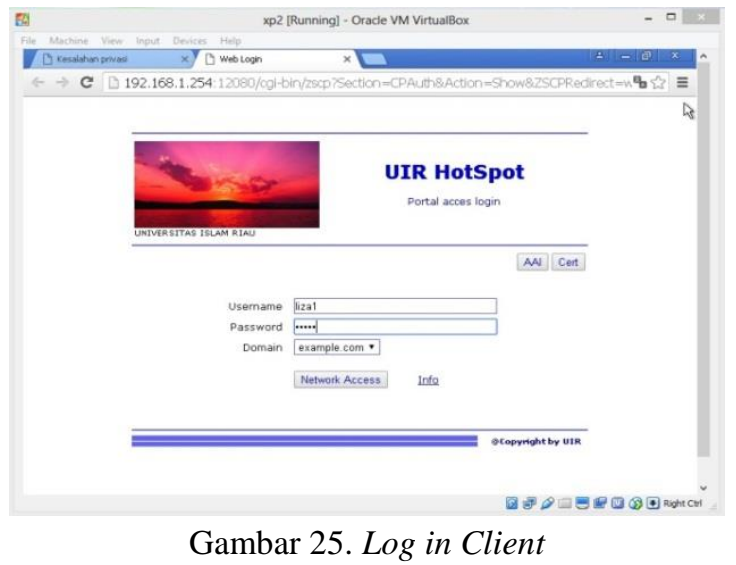

Pada gambar 25 merupakan contoh halaman $\log$ in user, sama seperti halaman log in admin yaitu dengan memasukkan username dan password. Jika otentikasi berhasil maka dapat dilihat pada gambar 26 dibawah ini. 


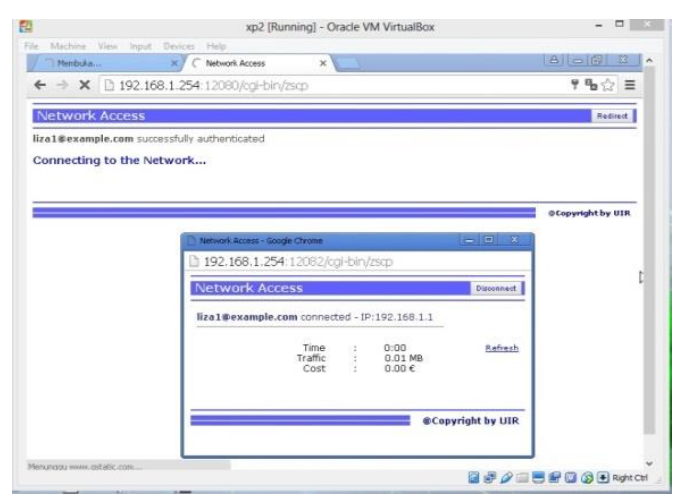

Gambar 26. Log in Client sukses

Pada gambar 26 diatas memberikan informasi bahwa user telah berhasil melakukan otentikasi jaringan dan bisa menggunakan jaringan UIR.

\section{Kesimpulan}

Dari hasil analisis pada bab sebelumnya pengujian Qos throughput dan delay menggunakan protocol EIGRP beserta otentikasi jaringan, maka dapat diambil kesimpulan sebagai berikut:

1. Topologi yang dibangun menggunakan topologi Star dan Ring dengan protocol EIGRP dengan AS number 100. Topologi Star lebih cocok digunakan untuk lingkungan UIR, karena router utama bisa terhubung ke semua fakultas UIR.

2.Dengan konfigurasi routing dynamic akan memudahkan admin dalam mengelola jaringan untuk jaringan berskala besar. Dengan protokol EIGRP memberikan backup route, sehingga konvergen waktu yang dibutuhkan dalam menganalisa jaringan cepat, dpat dilihat pada pengujian system saat penelusuran jalur.

3. Otentikasi radius server menggunakan zeroshell dapat berjalan dengan baik dengan protokol EIGRP.

4.Pemilihan jalur (path) yang cepat pada saat interface router mengalami masalah di LAN.

5.Nilai Qos throughput dan delay untuk routing protokol EIGRP memenuhi standar ITU-T G.114, dan nilai hasil pengujian rata-rata memiliki kualitas yang baik.

6.Nilai throughput dan nilai delay tidak berselisih begitu banyak pada setiap ping data yang dikirim memiliki rata-rata waktu yang baik untuk topologi jaringan UIR

\section{Saran}

Adapun saran yang perlu dikembangkan untuk penelitian selanjutnya adalah sebagai berikut:

1. Mensimulasikan untuk pengimplementasian IPv6 protokol EIGRP beserta otentikasi jaringan.

2.Simulasi lebih merincikan lagi secara detail tentang jaringan-jaringan yang terhubung dengan jaringan internal UIR.
3. Simulasi juga memberikan gambaran untuk menghitung QoS.

\section{DAFTAR PUSTAKA}

DABIN, JULIEN, 2014, Zeroshell Net Balancing, http://www.zeroshell.net/listing/Installation -et-configuration-de-Zeroshell.pdf

ERLANGGA, ADITYA , 2014, Menjaga Ketersediaan Koneksi Internet Dengan Metode FailOver, Universitas Gunadarma, http://www.undana.ac.id/jsmallfib_top/JUR NAL/ICT/ICT.pdf

GUNAWAN, 2015, Analisa Qos Video Streaming Dalam Jaringan MPLS IPv4 Berbasis Routing OSPF dan EIGRP, Skripsi. Universitas Islam Riau.

MERISA, 2015, Studi Kinerja Throughput Aplikasi Video/Voice di Jaringan IPv4/IPv6, Skripsi. Universitas Islam Riau.

PRIYONO, DWI, EFTI, 2012, Simulasi Routing Protocol OSPF Dan EIGRP Beserta Analisa Perbandingannya Dalam Menentukan Kinerja Yang Paling Baik, Skripsi. Universitas Muhammadiyah Surakarta.

SOFANA, IWAN, 2012, Cisco CCNP Dan Jaringan Komputer, Infomatika Bandung, Bandung.

SOFANA, IWAN, 2009, Cisco CCNA Dan Jaringan Komputer, Infomatika Bandung, Bandung.

SYAMSU, SURYADI, 2013, Jaringan Komputer, Andi Offset, Yogyakarta.

WIJAYA, CHANDRA, 2011, Simulasi Pemanfaatan Dynamic Routing Protokol OSPF Pada Router di Jaringan Komputer Unpar :Tesis M. T.

YUGIANTO, GINGIN DAN RACHMAN, OSCAR., 2012, Router, Informatika Bandung, Bandung.

ZUNAIDI, MUHAMMAD, et al. 2014 Membentuk jaringan Peer To Peer Menggunakan Kabel Firewire IEEE-1394 Dengan Metode Bridge, Vol. 13, No. 2. https://lppm.trigunadharma.ac.id/public/file Jurnal.pdf 